Behavioral/Cognitive

\title{
Elevation of Hippocampal Neurogenesis Induces a Temporally Graded Pattern of Forgetting of Contextual Fear Memories
}

\author{
Aijing Gao, ${ }^{1,2}$-Frances Xia, ${ }^{1,2}$ Axel J. Guskjolen, ${ }^{1,2}$ Adam I. Ramsaran, ${ }^{1,3}$ Adam Santoro, ${ }^{1,4}$ @Sheena A. Josselyn, ${ }^{1,2,3,4,5}$ \\ and $\odot$ Paul W. Frankland $1,2,3,4,6$ \\ ${ }^{1}$ Program in Neurosciences and Mental Health, The Hospital for Sick Children, Toronto, Ontario M5G 1X8, Canada, ${ }^{2}$ Department of Physiology, University \\ of Toronto, Toronto, Ontario M5S 1A8, Canada, ${ }^{3}$ Department of Psychology, University of Toronto, Toronto, Ontario M5S 3G3, Canada, ${ }^{4}$ Institute of \\ Medical Science, University of Toronto, Toronto, Ontario M5S 1A8, Canada, ${ }^{5}$ Brain, Mind \& Consciousness Program, Canadian Institute for Advanced \\ Research, Toronto, Ontario M5G 1M1, Canada, and ${ }^{6}$ Child \& Brain Development Program, Canadian Institute for Advanced Research, Toronto, Ontario \\ M5G 1M1, Canada
}

Throughout life neurons are continuously generated in the subgranular zone of the hippocampus. The subsequent integration of newly generated neurons alters patterns of dentate gyrus input and output connectivity, potentially rendering memories already stored in those circuits harder to access. Consistent with this prediction, we previously showed that increasing hippocampal neurogenesis after training induces forgetting of hippocampus-dependent memories, including contextual fear memory. However, the brain regions supporting contextual fear memories change with time, and this time-dependent memory reorganization might regulate the sensitivity of contextual fear memories to fluctuations in hippocampal neurogenesis. By virally expressing the inhibitory designer receptor exclusively activated by designer drugs, hM4Di, we first confirmed that chemogenetic inhibition of dorsal hippocampal neurons impairs retrieval of recent (day-old) but not remote (month-old) contextual fear memories in male mice. We then contrasted the effects of increasing hippocampal neurogenesis at recent versus remote time points after contextual fear conditioning in male and female mice. Increasing hippocampal neurogenesis immediately following training reduced conditioned freezing when mice were replaced in the context 1 month later. In contrast, when hippocampal neurogenesis was increased time points remote to training, conditioned freezing levels were unaltered when mice were subsequently tested. These temporally graded forgetting effects were observed using both environmental and genetic interventions to increase hippocampal neurogenesis. Our experiments identify memory age as a boundary condition for neurogenesis-mediated forgetting and suggest that, as contextual fear memories mature, they become less sensitive to changes in hippocampal neurogenesis levels because they no longer depend on the hippocampus for their expression.

Key words: fear conditioning; forgetting; hippocampus; memory; neurogenesis

Significance Statement

New neurons are generated in the hippocampus throughout life. As they integrate into the hippocampus, they remodel neural circuitry, potentially making information stored in those circuits harder to access. Consistent with this, increasing hippocampal neurogenesis after learning induces forgetting of the learnt information. The current study in mice asks whether these forgetting effects depend on the age of the memory. We found that post-training increases in hippocampal neurogenesis only impacted recently acquired, and not remotely acquired, hippocampal memories. These experiments identify memory age as a boundary condition for neurogenesis-mediated forgetting, and suggest remote memories are less sensitive to changes in hippocampal neurogenesis levels because they no longer depend critically on the hippocampus for their expression.

\section{Introduction}

The continued integration of new neurons into hippocampal circuits throughout adulthood has been hypothesized to impact memory function in two ways (Frankland et al., 2013). First, freshly integrated neurons provide new substrates for learning and therefore might facilitate the formation of new memories
Received 0ct. 31, 2017; revised Jan. 16, 2018; accepted Feb. 12, 2018

Author contributions: A.G., F.X., A.J.G., A.I.R., A.S., S.A.J., and P.W.F. designed research; A.G., F.X., A.J.G., A.I.R., and A.S. performed research; A.G., F.X., and A.I.R. analyzed data; F.X., S.A.J., and P.W.F. wrote the paper.

This work was supported by Canadian Institutes of Health Research Grant FDN143227 to P.W.F. and Grant MOP74650 to S.A.J.
The authors declare no competing financial interests.

Correspondence should be addressed to Dr. Paul W. Frankland, Program in Neurosciences and Mental Health, The Hospital for Sick Children, Toronto, Ontario M5G 1X8, Canada. E-mail: paul.frankland@sickkids.ca.

DOI:10.1523/JNEUROSCI.3126-17.2018

Copyright $\odot 2018$ the authors $\quad 0270-6474 / 18 / 383190-09 \$ 15.00 / 0$ 
(e.g., by increasing capacity or allowing more efficient pattern separation). This view is supported by studies showing that suppression of hippocampal neurogenesis typically impairs new memory formation (Shors et al., 2001; Saxe et al., 2006; Clelland et al., 2009; Zhuo et al., 2016), whereas promotion of hippocampal neurogenesis may improve memory acquisition (van Praag et al., 1999a; Creer et al., 2010; Sahay et al., 2011; Stone et al., 2011). Second, by modifying the pattern of dentate gyrus input and output connections, the integration of new neurons alters hippocampal circuits and therefore may render memories already stored in these circuits harder to access at later time points. Using genetic, pharmacological, and environmental interventions to elevate neurogenesis, we provided support for this latter idea. Increasing neurogenesis after memory formation in mice, guinea pigs, and degus induced forgetting of hippocampus-dependent memories (Akers et al., 2014; Epp et al., 2016; Ishikawa et al., 2016; but for a possible exception in rats, see Kodali et al., 2016).

While the formation and initial expression of event memories depend on the hippocampus, over time contextual fear memories become less dependent upon the hippocampus for their expression and more dependent on the cortex (Frankland and Bontempi, 2005). For example, when rats learn an association between a context and shock, lesioning the hippocampus $1 \mathrm{~d}$ following training induces loss of this contextual fear memory. However, similar lesions at more remote time points have no effect (Kim and Fanselow, 1992; Anagnostaras et al., 1999). This pattern of temporally graded retrograde amnesia following hippocampal damage predicts that, as contextual fear memories mature and become successfully consolidated in the cortex, they should become less vulnerable to neurogenesis-mediated forgetting. Here we used chemogenetic methods to first establish that the dorsal hippocampus plays a time-limited role in the expression of contextual fear memories in mice. Then we tested the impact of experimentally elevating hippocampal neurogenesis on recently versus remotely acquired contextual fear memories. Using both naturalistic (exercise) and genetic (conditional deletion of p53 from neural progenitors) interventions to elevate neurogenesis, we found that elevating neurogenesis weakened only recently, and not remotely acquired, contextual fear memories.

\section{Materials and Methods}

Mice

All procedures were approved by the Animal Care and Use Committee at the Hospital for Sick Children. In these experiments, we used two lines of mice. First, in Experiments 1-5, we used wild-type (WT) derived from a cross between $129 \mathrm{~S} 6$ and C57BL/6N mice (Taconic Farms). Second, in Experiment 6, we used mice in which conditional deletion of the tumor suppressor gene $p 53$ in nestin ${ }^{+}$cells increases hippocampal neurogenesis (Akers et al., 2014). The latter mice were generated by crossing nestin ${ }^{\mathrm{Cr} E R T 2+}$ mice, which express a tamoxifen (TAM)inducible form of Cre-recombinase driven by a progenitor-specific (nestin) promoter (line 5 from Imayoshi et al., 2008), with mice in which the $p 53$ gene is floxed by two loxP sites ( $p 53^{f / f}$ ) (Marino et al., 2000). Accordingly, in male and female offspring from this cross, injection of TAM leads to deletion of $p 53$ only in nestin ${ }^{+}$cells and their progeny (inducible knock-out of $p 53$, or $i K O-p 53)$. Both lines were maintained on a C57BL/6N background. Genotypes were determined by PCR analysis of tail DNA samples, as previously described (Arruda-Carvalho et al., 2011; Akers et al., 2014). TAM (Sigma-Aldrich) was dissolved in sunflower seed oil containing $10 \%$ ethanol and injected $(180 \mathrm{mg} / \mathrm{kg}$, i.p.) into mice once per day for 5 consecutive days.

Mice were bred in the animal facility at The Hospital for Sick Children and maintained on a $12 \mathrm{~h} \mathrm{light/dark} \mathrm{cycle} \mathrm{(lights} \mathrm{on} \mathrm{at} 0700 \mathrm{~h}$ ). Mice were group-housed $(2-5$ per cage $)$ in transparent plastic cages $(31 \times 17 \times 14$ $\mathrm{cm}$ ) with free access to food and water unless otherwise specified. Behavioral testing began when mice were $8-10$ weeks of age.

\section{Viral microinfusion}

AAV8-CaMKII $\alpha$-hM4Di-mCitrine virus was obtained from UNC Vector Core (Chapel Hill, NC). Control virus (AAV(DJ)-CMV-GFP) was produced in house. Four weeks before behavior, WT mice were microinfused bilaterally with either the hM4Di or control viral vectors ( $1.5 \mu \mathrm{l}$ per side, $0.1 \mu \mathrm{l} / \mathrm{min}$ infusion rate) in the CA1 ( $-1.9 \mathrm{~mm}$ anteroposterior, $\pm 1.3 \mathrm{~mm}$ mediolateral, $-1.5 \mathrm{~mm}$ dorsoventral) from bregma according to Paxinos and Franklin (2012).

\section{Drug}

Clozapine- $\mathrm{N}$-oxide (CNO, kindly provided by Dr. Bryan Roth, University of North Carolina) was dissolved in DMSO and administered at a dose of $5 \mathrm{mg} / \mathrm{kg}$ for intraperitoneal injections. The Vehicle (Veh) control groups received the equivalent amount of DMSO solution dissolved in $0.9 \%$ saline. Mice received $\mathrm{CNO}$ or Veh injection $30 \mathrm{~min}$ before fear memory retrieval tests.

\section{Contextual fear conditioning}

Contextual fear conditioning occurred in test chambers $(31 \mathrm{~cm} \times 24$ $\mathrm{cm} \times 21 \mathrm{~cm}$; Med Associates) with shock-grid floors (bars $3.2 \mathrm{~mm}$ in diameter spaced $7.9 \mathrm{~mm}$ apart). The front, top, and back of the chamber were clear acrylic and the two sides were modular aluminum. During training, mice were placed in the chambers, and 3 foot shocks $(0.5 \mathrm{~mA}, 2 \mathrm{~s}$ duration, $1 \mathrm{~min}$ apart) were delivered after $2 \mathrm{~min}$. Mice were removed 1 min after the last shock. During testing, mice were placed in the chambers for $5 \mathrm{~min}$. For the experiment involving the $i K O-p 53$ mice, shock intensity was $0.7 \mathrm{~mA}$, and mice were tested for $3 \mathrm{~min}$ (rather than $5 \mathrm{~min}$ ). Behavior was recorded by overhead cameras. Freezing (i.e., absence of movement except for breathing) was measured using an automated scoring system (Actimetrics).

\section{Running}

Mice in running groups were given voluntary access to a running wheel (Med Associates ENV-044) placed in their home cage. Mice in sedentary groups were housed conventionally. Using identical apparatus and procedures, we previously showed that mice run an average of $4.7 \pm 0.53 \mathrm{~km}$ per day in these conditions (Akers et al., 2014), similar to previous studies (van Praag et al., 1999b).

\section{Specific experimental procedures}

Experiment 1. A $2 \times 2 \times 2$ design was used in this experiment with virus (control vs hM4Di), delay (immediate vs delay), and drug (Veh vs CNO) as between-subject variables. Male mice were randomly assigned to groups, and fear conditioned and then tested either 1 or $28 \mathrm{~d}$ later. Thirty minutes before testing, mice were treated with Veh (control virus, $1 \mathrm{~d}$ test, $n=8$; hM4Di virus, $1 \mathrm{~d}$ test, $n=7$; control virus, $28 \mathrm{~d}$ test, $n=7$; hM4Di virus, $28 \mathrm{~d}$ test, $n=8$ ) or CNO (control virus, $1 \mathrm{~d}$ test, $n=8$; hM4Di virus, $1 \mathrm{~d}$ test, $n=12$; control virus, $28 \mathrm{~d}$ test, $n=8$; hM4Di virus, $28 \mathrm{~d}$ test, $n=12$ ).

Experiment 2. Male and female mice were fear conditioned and then tested $28 \mathrm{~d}$ later. During this retention delay, mice had home cage access to a running wheel (male, $n=8$; female, $n=11$ ) or were housed conventionally (male, $n=8$; female, $n=8$ ).

Experiment 3. Female mice were fear conditioned and then tested $28 \mathrm{~d}$ later. During this retention delay, mice had home cage access to a running wheel for $0(n=8), 7(n=12), 14(n=8)$, or $28(n=12) \mathrm{d}$, starting immediately after training.

Experiments 4-6. In Experiment 4, female mice were fear conditioned and then tested either 28 or $56 \mathrm{~d}$ later. For the groups tested $28 \mathrm{~d}$ later, mice had home cage access to a running wheel from days 1-14 following training $(n=12)$ or were housed conventionally $(n=12)$. For the groups tested $56 \mathrm{~d}$ later, mice had home cage access to a running wheel from days 29-42 following training $(n=10)$ or were housed conventionally $(n=12)$.

In Experiment 5, female mice were fear conditioned and then tested $28 \mathrm{~d}$ later. Approximately half the mice had home cage access to a running wheel from days $1-14$ following training $(n=8)$ or were housed 


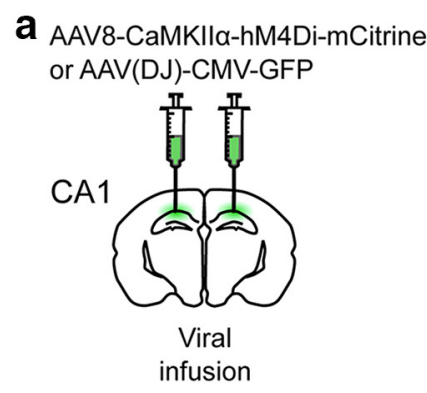

c

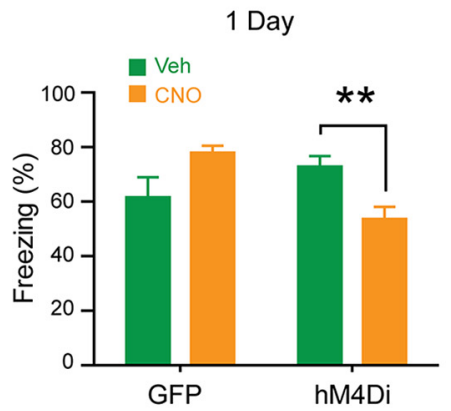

28 Days

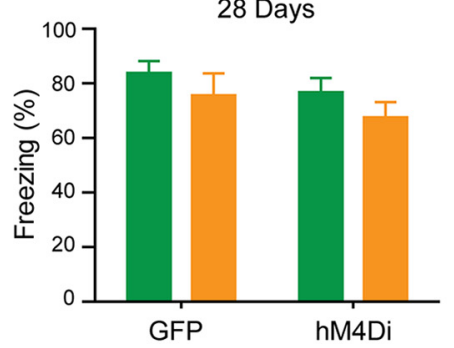

b

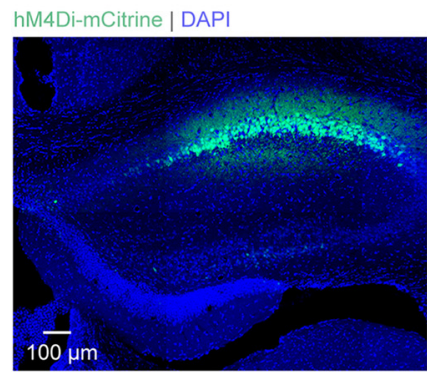

d

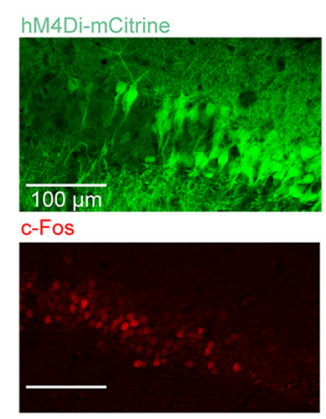

Merged

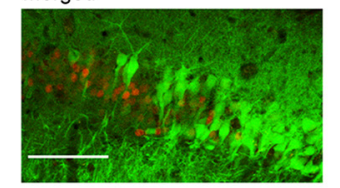

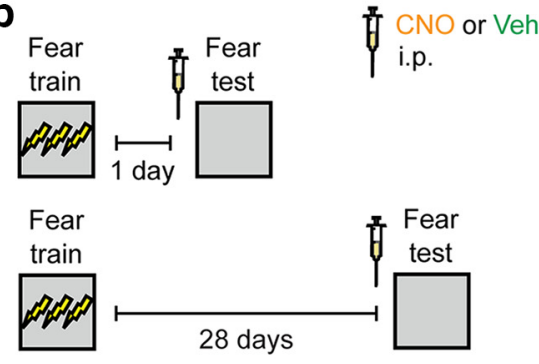

e

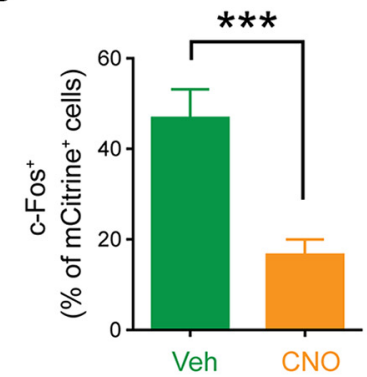

Figure 1. Chemogenetic inhibition of dorsal hippocampus impairs expression of recent, but not remote, contextual fear memory. $\boldsymbol{a}$, Representative images showing hM4Di expression in a WT mouse that was microinfused with AAV8-CaMKII $\alpha$-hM4Di-mCitrine virus in the CA1. $\boldsymbol{b}$, Mice were trained in contextual fear conditioning and tested 1 or $28 \mathrm{~d}$ after training. Thirty minutes before testing, mice received an intraperitoneal injection of $\mathrm{CNO}$ or Veh. $c$, Compared with Veh treatment, CNO treatment before the $1 \mathrm{~d}$ test resulted in lower freezing only in the group that received hM4Di virus infusion (hM4Di), but not in the group that received control virus (GFP). In contrast, CN0 treatment before the $28 \mathrm{~d}$ test had no effect on fear memory expression, in both the hM4Di and GFP virus groups. $\boldsymbol{d}$, Representative images showing c-Fos ${ }^{+}$, hM4Di-mCitrine ${ }^{+}$, and c-Fos ${ }^{+} / \mathrm{hM}_{\text {DDi-mCitrine }}{ }^{+}$neurons. $\boldsymbol{e}$, Compared with Veh-treated mice, CN0-treated mice showed reduced colocalization of c-Fos and hM4Di-mCitrine following fear conditioning testing. ${ }^{* *} p<0.01$; ${ }^{* * *} p<0.001$.

conventionally $(n=7)$. The remaining mice had home cage access to a running wheel from days $15-28(n=11)$ or were housed conventionally $(n=12)$.

In Experiment 6, male and female mice were fear conditioned and then tested $42 \mathrm{~d}$ later. Mice had home cage access to a running wheel on days $1-28$ (immediate group; $n=16$ ) or $15-42 \mathrm{~d}$ (delay group; $n=16$ ) following training, or were housed conventionally throughout the retention delay (sedentary group; $n=16$ ).

Experiment 7. Mice were fear conditioned and then tested either 28 or $56 \mathrm{~d}$ later. For the groups tested $28 \mathrm{~d}$ later, WT $(n=11)$ and $i K O-p 53$ $(n=13)$ mice were treated with TAM starting immediately following training. For the groups tested $56 \mathrm{~d}$ later, WT $(n=8)$ and $i K O-p 53(n=$ 7) mice were treated with TAM starting $29 \mathrm{~d}$ following training.

\section{Immunohistochemistry}

Mice were perfused transcardially with PBS followed by $4 \%$ PFA. Brains were postfixed in PFA and transferred to $30 \%$ sucrose. Coronal sections $(50 \mu \mathrm{m})$ were cut along the entire anterior-posterior extent of the CA1 or DG using a cryostat. For doublecortin (DCX) labeling, sections were incubated with primary (goat anti-DCX, 1:600, Santa Cruz Biotechnology) and secondary (donkey anti-goat, 1:300, Invitrogen) antibodies. DAPI (1:1000, Sigma-Aldrich) was used as a counterstain. For c-Fos labeling, sections were incubated with primary (rabbit anti-c-Fos, 1:1000, Santa Cruz Biotechnology) and secondary (goat anti-rabbit, 1:500, Thermo Fisher Scientific) antibodies. Images were obtained using a confocal laser scanning microscope (LSM 710; Carl Zeiss).
Analyses

Data were analyzed using ANOVA or two-tailed $t$ tests. Planned comparisons or post hoc (Bonferroni) tests were used where appropriate. Statistical significance was set at $p<0.05$.

\section{Results}

Chemogenetic inhibition of dorsal hippocampus impairs expression of recent, but not remote, contextual fear memory We first tested whether the activity of dorsal hippocampal neurons is required for the expression of day-old versus month-old contextual fear memories. To do this, mice received microinfusions of an AAV virus expressing the inhibitory designer receptor exclusively activated by designer drugs, hM4Di or GFP into the CA1 of the dorsal hippocampus (Fig. 1a). They were subsequently fear conditioned and then tested either 1 or $28 \mathrm{~d}$ later. Thirty minutes before this test, mice received an intraperitoneal injection of $\mathrm{CNO}$ or Veh (Fig. 1b). CNO treatment appeared to selectively reduce freezing levels in hM4Di-infected mice at the $1 \mathrm{~d}$ retention delay (Fig. 1c). An ANOVA with virus (control vs hM4Di), delay (immediate vs delay), and drug (Veh vs CNO) as between-subject variables was conducted on the data. There was a significant three-way interaction $\left(F_{(1,62)}=4.71, p=0.034\right)$. To analyze the source of the significant three-way interaction, we used planned comparisons, which focused on CNO versus Veh effects in 
a

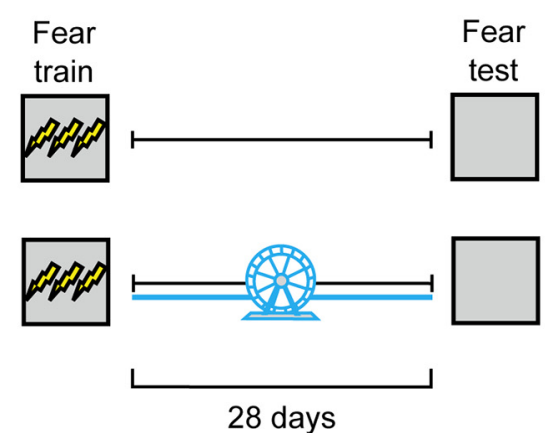

C
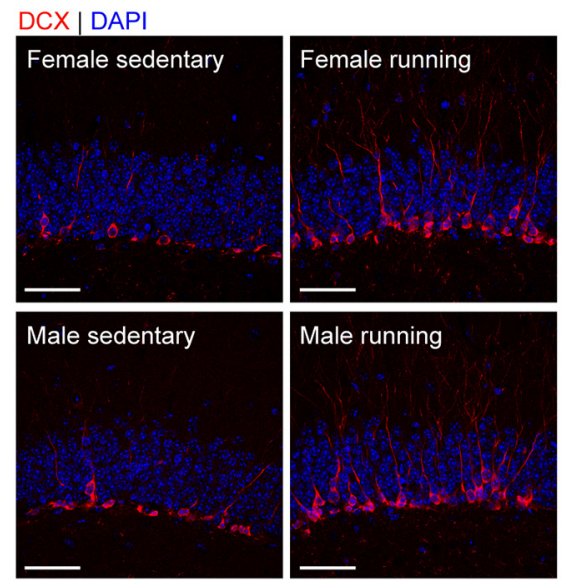

b

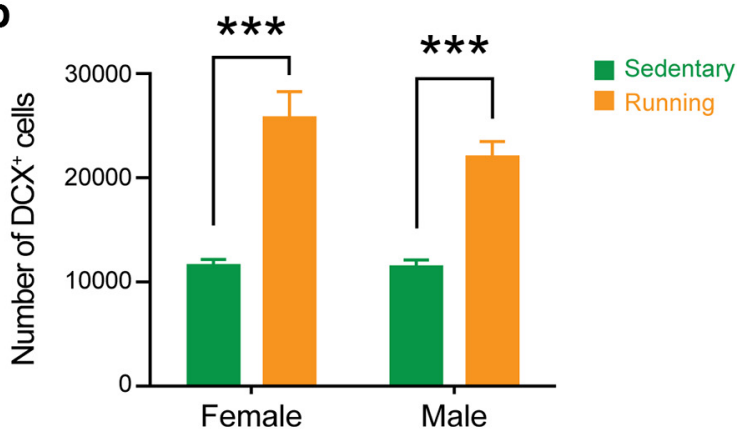

d

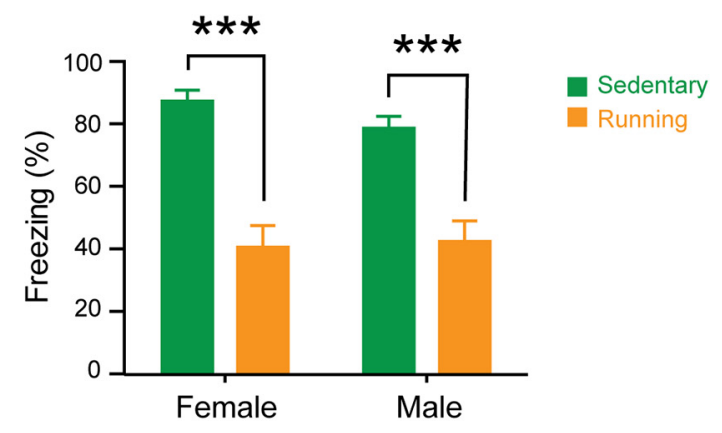

Figure 2. Post-training voluntary exercise induces forgetting of contextual fear memories in male and female mice. $\boldsymbol{a}$, WT male and female mice were trained in contextual fear conditioning and given home cage access to running wheel for $28 \mathrm{~d}$. Contextual fear memory was assessed $28 \mathrm{~d}$ after training. $\boldsymbol{b}$, Running increased the number of $D C X^{+}$cells in both female and male mice, compared with sedentary controls. c, Representative images showing increased number of DCX ${ }^{+}$cells in DG, in female and male mice. Scale bar, $50 \mu m$. $\boldsymbol{d}$, Running decreased the level of freezing in both female and male mice, compared with sedentary controls (female, $n=11$; male, $n=8$ ). ${ }^{* *} p<0.001$.

hM4Di- and GFP-infected mice at recent and remote time points. These comparisons indicated that $\mathrm{CNO}$ treatment reduced freezing levels only in mice expressing hM4Di in CA1, and tested $1 \mathrm{~d}$ following training $\left(t_{(17)}=3.06, p=0.007\right)$. Immunohistological analyses confirmed that $\mathrm{CNO}$ treatment reduced activation of hM4Di-infected neurons (Fig. $1 d$,e; CNO, $n=6$; Veh, $n=8$; $\left.t_{(12)}=4.51, p=0.007\right)$.

Post-training voluntary exercise induces forgetting of contextual fear memories in male and female mice

In our previous study, we showed that post-training exercise increases hippocampal neurogenesis and induces forgetting of contextual fear memories (Akers et al., 2014). We first sought to replicate this finding, and by testing both male and female mice, additionally evaluate whether there were any sex differences in the degree of exercise-induced forgetting. Accordingly, male and female mice were trained in contextual fear conditioning and then given home cage access to an exercise wheel for $28 \mathrm{~d}$ or housed conventionally. All mice were tested $28 \mathrm{~d}$ after conditioning (Fig. 2a). Post-training exercise was associated with an increase in the number of cells expressing the immature neuronal marker, $\mathrm{DCX}^{+}$, in the subgranular zone of the hippocampus in both male and female mice ( $n=4$ for all groups; Factorial Exercise $\times$ Sex ANOVA, Exercise: $F_{(1,12)}=67.85, p<0.0001$; Sex: $F_{(1,12)}=1.65, p=0.22$; Exercise $\times$ Sex interaction: $F_{(1,12)}=1.47$, $p=0.25$ ) (Fig. $2 b, c$ ). As we previously observed (Akers et al., 2014), levels of conditioned freezing were reduced in mice that ran after training (female: sedentary $n=8$, running $n=11$; male: sedentary $n=8$, running $n=8$; Factorial Exercise $\times$ Sex ANOVA, Exercise: $\left.F_{(1,31)}=49.49, p<0.0001\right)$. Furthermore, the degree of forgetting did not differ between male and female mice (Sex: $F_{(1,31)}=0.33, p=0.57$; Exercise $\times$ Sex interaction: $F_{(1,31)}=0.78$, $p=0.38)$ (Fig. 2d).

\section{Post-training voluntary exercise induces forgetting of} contextual fear memories in a dose-dependent manner We next evaluated how much post-training exercise is required to induce forgetting. To do this, different groups of female mice were trained in contextual fear conditioning and then given home cage access to an exercise wheel for $0,7,14$, or $28 \mathrm{~d}$. All mice were tested $28 \mathrm{~d}$ after conditioning (Fig. 3a). Exercise duration influenced hippocampal neurogenesis, with longer duration exercise associated with higher numbers of immature $\left(\mathrm{DCX}^{+}\right)$neurons in the dentate gyrus (Fig. $3 b)(0 \mathrm{~d}: n=4 ; 7 \mathrm{~d} n=4 ; 14 \mathrm{~d} n=5 ; 28 \mathrm{~d} n=$ $\left.4 ; F_{(3,13)}=21.86, p<0.0001\right)$. Post hoc analyses indicated that there were greater numbers of $\mathrm{DCX}^{+}$cells in the 14 and $28 \mathrm{~d}$ groups compared with the $0 \mathrm{~d}$ group $(p=0.002$, and $p<0.0001$, respectively). Exercise duration also influenced levels of conditioned fear ( $0 \mathrm{~d}: n=8 ; 7 \mathrm{~d} n=12 ; 14 \mathrm{~d} n=8 ; 28 \mathrm{~d} n=12 ; F_{(3,39)}=$ $6.12, p=0.002$ ), with mice exercising for 14 or $28 \mathrm{~d}$ exhibiting reduced levels of conditioned fear compared with sedentary controls $(p=0.01$, and $p=0.003$, respectively) (Fig. $3 c$ ). These data suggest that $14 \mathrm{~d}$ of exercise is sufficient to induce forgetting. Furthermore, the absence of forgetting in the mice that exercised for $7 \mathrm{~d}$ following conditioning excludes the possibility that expo- 
a

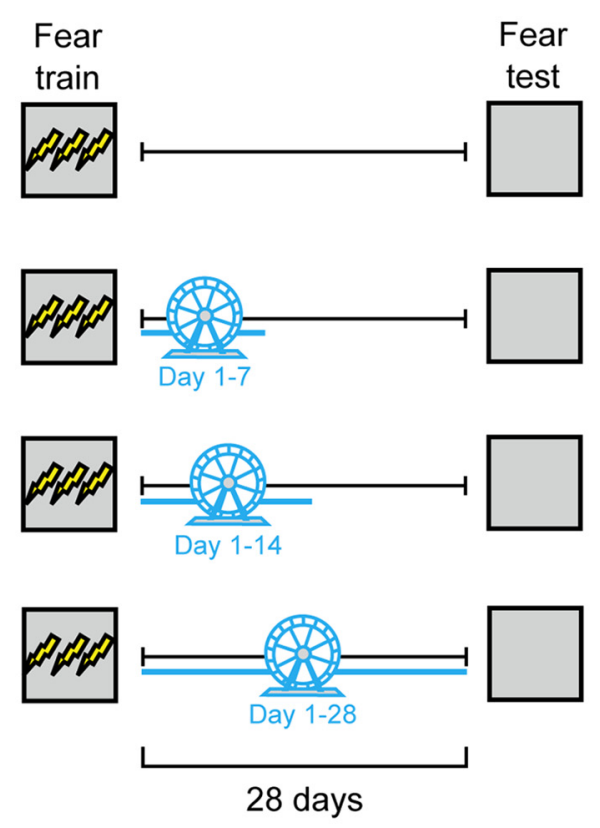

b

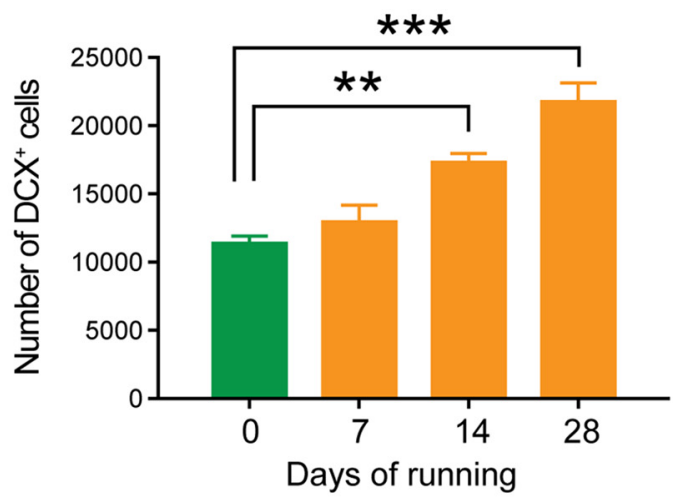

C

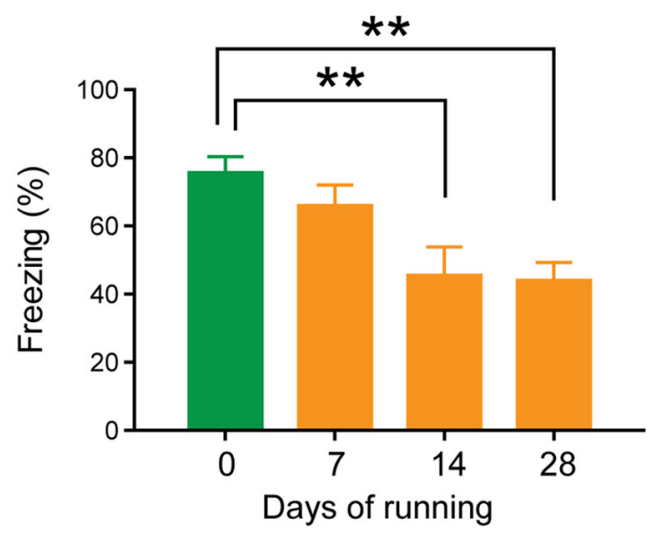

Figure 3. Post-training voluntary exercise induces forgetting of contextual fear memories in a dose-dependent manner. $\boldsymbol{a}$, Mice were trained in contextual fear conditioning and given access to running wheel for $0,7,14$, or $28 \mathrm{~d}$. Contextual fear memory was assessed $28 \mathrm{~d}$ after training. $\boldsymbol{b}$, Running increased the number of $D C X^{+}$cells in a dose-dependent manner. $\boldsymbol{c}$, Running decreased the levels of freezing in a dose-dependent manner. ${ }^{* *} p<0.01 ;{ }^{* * *} p<0.001$.

sure to a novel object (running wheel) following learning induces forgetting, as we have previously shown (Akers et al., 2014).

\section{Voluntary exercise induces a temporally graded pattern of forgetting}

Expression of contextual fear memories initially depends on the hippocampus. However, expression of these memories becomes less dependent on the hippocampus and more dependent on cortical structures at more remote time points (Frankland et al., 2013). Therefore, artificial elevation of hippocampal neurogenesis should impact recently acquired contextual fear memories to a greater degree than remotely acquired contextual fear memories. To test whether remote contextual fear memories are relatively invulnerable to increases in hippocampal neurogenesis, different groups of mice were trained in contextual fear conditioning. Following conditioning, mice had running wheel access for $14 \mathrm{~d}$ in their home cage starting either immediately following training or after a $28 \mathrm{~d}$ delay. Fourteen days following removal of the running wheel, mice were placed back in the conditioning context and freezing was assessed (Fig. 4a). Mice that exercised immediately following training $(n=12)$ exhibited lower levels of conditioned freezing compared with sedentary control mice $(n=$ 12). In contrast, in the delay condition, runner $(n=10)$ and sedentary $(n=12)$ mice exhibited equivalent levels of conditioned freezing (Fig. 4b). The time-dependent effects of exercise on forgetting were supported by an ANOVA with Time (immediate vs delay) and Exercise (sedentary vs running) as betweensubject variables. There was a main effect of Exercise $\left(F_{(1,42)}=\right.$ $11.96, p=0.001)$ and Time $\times$ Exercise interaction $\left(F_{(1,42)}=5.55\right.$, $p=0.023)$. Post hoc tests indicated that runner mice froze more than sedentary mice in the immediate, but not delay, condition $(p=0.003)$. There was no main effect of Time $\left(F_{(1,42)}=1.44\right.$, $p=0.23)$.

In the above experiment, freezing levels in sedentary mice were lower at the $56 \mathrm{~d}$ retention delay versus $28 \mathrm{~d}$ retention delay. Therefore, it is possible that a floor effect masks the effects of increasing hippocampal neurogenesis in the delay group. To address this potential confound, we conducted two additional experiments in which we used a shorter, fixed retention delay and varied the timing of exercise. In the first experiment, we used a $28 \mathrm{~d}$ retention delay between training and testing. Mice then were given home cage access to a running wheel for $14 \mathrm{~d}$ starting either immediately following training or after a $14 \mathrm{~d}$ delay (Fig. $4 c$ ). Only exercise immediately following training-induced forgetting (Factorial Time $\times$ Exercise ANOVA, Time: $F_{(1,34)}=3.62, p=$ 0.07; Exercise: $F_{(1,34)}=17.61, p=0.0002$; Time $\times$ Exercise interaction: $\left.F_{(1,34)}=4.45, p=0.042\right)$, with runner mice $(n=8)$ freezing less than sedentary mice $(n=7)$ in the immediate $(p=$ 0.0017 ), but not delay (sedentary: $n=12$; running: $n=11$ ), condition ( $p=0.63$ ) (Fig. $4 d$ ). Comparison of the runner groups indicated that mice in the immediate condition froze less than those in the delay condition $(p=0.042)$.

In the second experiment, we used a $42 \mathrm{~d}$ retention delay between training and testing. Mice then were given home cage access to a running wheel for $28 \mathrm{~d}$ starting either immediately following training or after a $14 \mathrm{~d}$ delay (Fig. 4e). Only exercise immediately following training-induced forgetting (one-way ANOVA, Time: $\left.F_{(2,45)}=11.33, p=0.0001\right)$, with runner mice $(n=16)$ freezing less than sedentary mice $(n=16)$ in the immediate $(p<0.0001)$, but not delay $(n=16)$, condition $(p=0.57)$ 
a
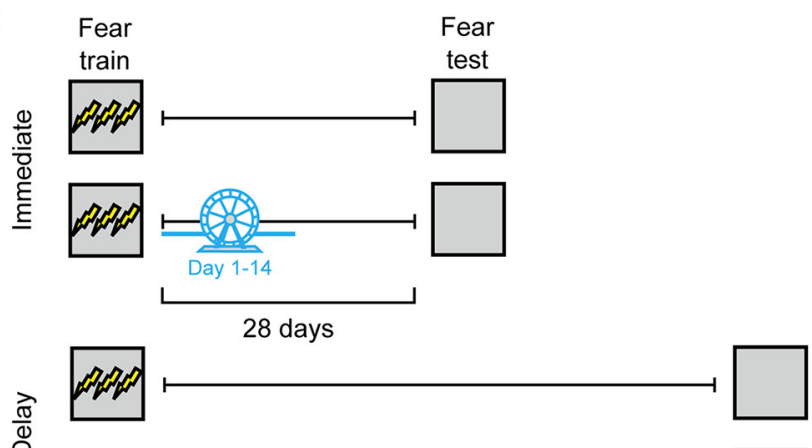

อ

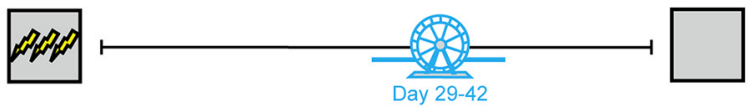

56 days

C
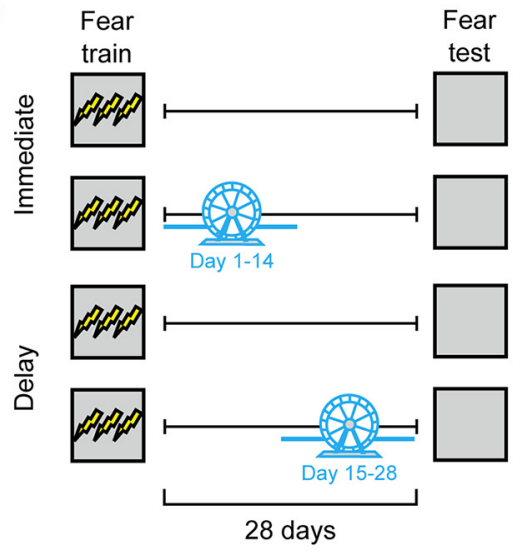

e

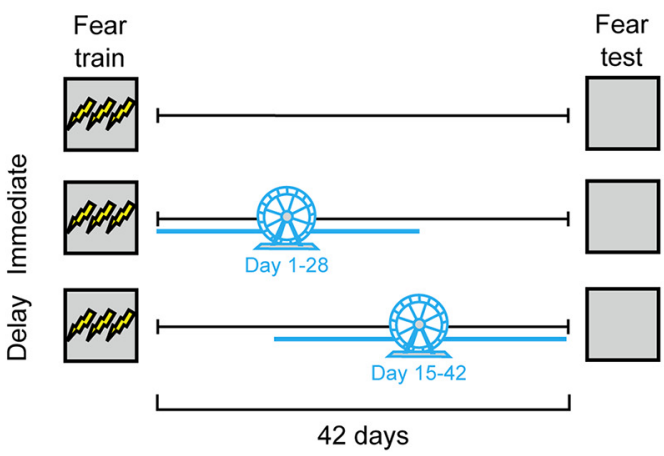

b

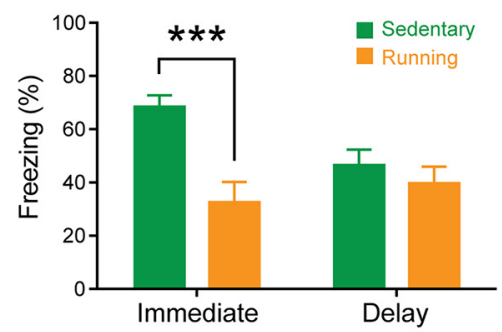

d

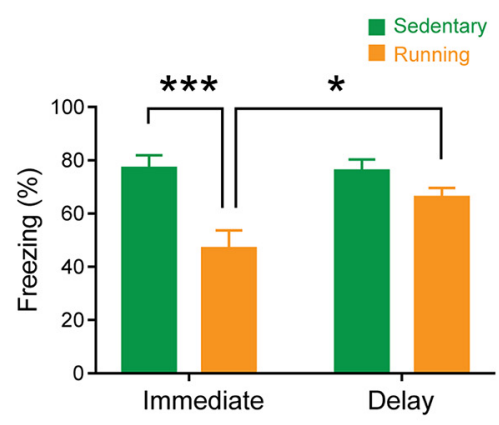

f

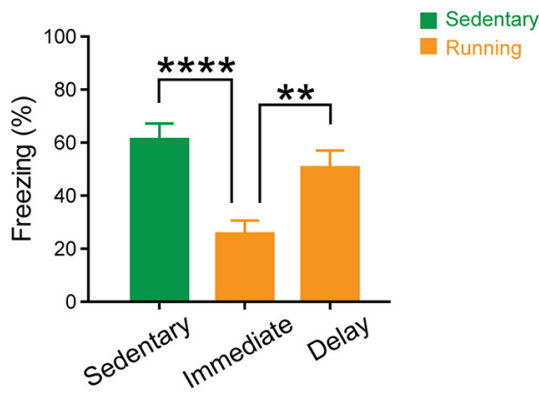

Figure 4. Voluntary exercise induces a temporally graded pattern of forgetting. $\boldsymbol{a}$, Mice were trained in contextual fear conditioning and given access to running wheel from day $1-14$ (immediate condition) or day $29-42$ (delay condition). Contextual fear memory was assessed $14 \mathrm{~d}$ following the end of running wheel period (i.e., on day 28 or 56 for the immediate and delay conditions, respectively). $\boldsymbol{b}$, Running reduced the level of freezing in the immediate, but not delay, condition. $\boldsymbol{c}$, Mice were trained in contextual fear conditioning, and given access to running wheel from day 1-14 (immediate condition) or day 14-28 (delay condition). Contextual fear memory was assessed $28 \mathrm{~d}$ after training. $\boldsymbol{d}$, Running reduced the levels of freezing in the immediate, but not the delay, condition. $\boldsymbol{e}$, Mice were trained in contextual fear conditioning and given access to running wheel from day 1-28 (immediate) or day 15- 42 (delay). Contextual fear memory was assessed $42 \mathrm{~d}$ after training. $f$, Running reduced the levels of freezing in the immediate, but not delay, condition. ${ }^{*} p<0.05 ;{ }^{* *} p<0.01 ;{ }^{* * *} p<0.001 ;{ }^{* * * *} p<0.0001$.

(Fig. $4 f)$. Comparison of the runner groups indicated that mice in the immediate condition froze less than those in the delay condition $(p=0.0058)$. These two experiments indicate that temporally graded forgetting effects are observed regardless of whether conditioned freezing levels decline, or are stable, across the retention delay.

\section{Conditional deletion of $p 53$ from neural progenitor cells leads to forgetting of recent, but not remote, contextual fear memories}

We next tested whether nonrunning interventions that increase neurogenesis might similarly induce a temporally graded pattern of forgetting of established memories. To do this, we crossed mice that express a TAM-inducible Cre-recombinase in nestin ${ }^{+}$cells (nestin ${ }^{\text {creERT2 }}$ ) with mice in which the tumor suppressor gene $p 53$ is flanked by two loxP sites $\left(p 53^{f / f}\right)$. In adult offspring from this cross, TAM treatment induces deletion of $p 53$ in nestin ${ }^{+}$cells, which results in increased neurogenesis (iKO-p53) (Akers et al., 2014). iKO-p53 and littermate control mice were trained in contextual fear conditioning. Then either immediately following training or after a $28 \mathrm{~d}$ delay, mice were treated with TAM. Twenty-eight days following TAM treatment, contextual fear memory was assessed (Fig. 5a). As we observed previously (Akers et al., 2014), 
a

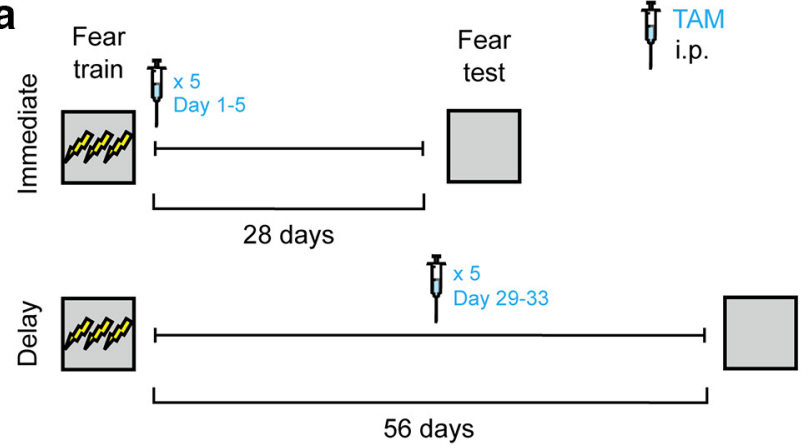

b

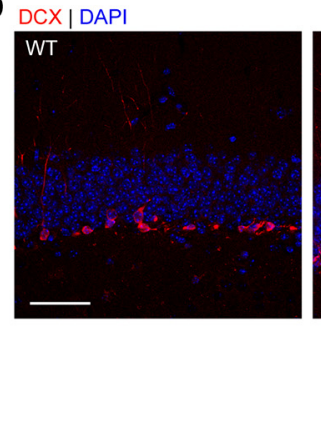

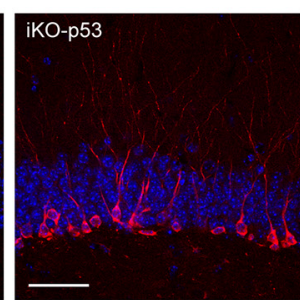

C

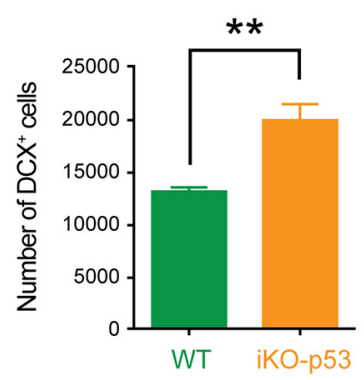

d

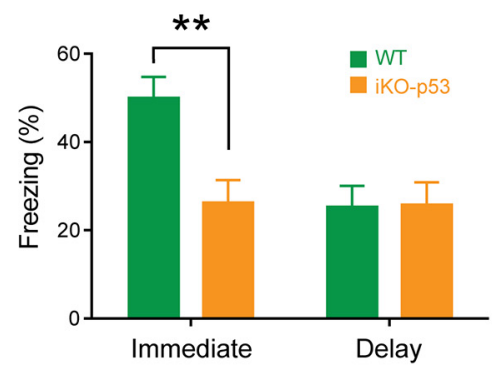

Figure 5. Conditional deletion of $p 53$ from neural progenitor cells leads to forgetting of recent, but not remote, contextual fear memories. $\boldsymbol{a}$, iK0-p53 and control WT mice were trained in contextual fear conditioning and treated with TAM $1 \mathrm{~d}$ (immediate condition) or $28 \mathrm{~d}$ (delay condition) later. Contextual fear memory was assessed $28 \mathrm{~d}$ after TAM treatment. $\boldsymbol{b}$, Representative images showing that showed increased number of DCX ${ }^{+}$cells in DG in an iKO-p53 mouse compared with a control WT mouse. Scale bar, $50 \mu \mathrm{m} . c_{,}, i K 0-p 53$ mice showed increased number of DCX ${ }^{+}$ cells in DG compared with WT mice. $d$, Conditional deletion of $p 53$ reduced levels of freezing in the immediate, but not delay, condition. ${ }^{* *} p<0.01$.

conditional deletion of $p 53$ increased hippocampal neurogenesis $\left(t_{(7)}=5.12, p=0.0014\right.$ ) (Fig. 5b,c). Moreover, similar to exercise, conditional deletion of $p 53(n=13)$ immediately following training induced forgetting of contextual fear memory, compared with controls $(n=11)$. In contrast, in the delay condition, $i K O$ p53 $(n=7)$ and control mice $(n=8)$ exhibited equivalent levels of conditioned freezing (Fig. $5 d$ ). These time-dependent effects of p53 deletion on forgetting were supported by an ANOVA with Time (immediate vs delay) and Genotype ( $i K O-p 53$ vs control) as between-subject variables. There were main effects of Time $\left(F_{(1,35)}=5.75, p=0.022\right)$, Genotype $\left(F_{(1,35)}=4.89, p=0.034\right)$, and a Time $\times$ Genotype interaction $\left(F_{(1,35)}=5.33, p=0.027\right)$. Post hoc tests indicated that control mice froze more than $i K O$ $p 53$ mice in the immediate $(p=0.0017)$, but not delay $(p>$ $0.99)$, condition. Together with published data showing that preventing exercise-induced increases in hippocampal neurogenesis prevents forgetting (Akers et al., 2014; Epp et al., 2016), these data support the conclusion that these effects are mediated by a neurogenesis-dependent mechanism. Furthermore, they provide additional evidence that the forgetting effects depend on memory age.

\section{Discussion}

In this paper, we present two main findings. First, by virally expressing the inhibitory designer receptor exclusively activated by designer drugs, hM4Di in the dorsal hippocampus, we confirmed that suppressing activity of dorsal hippocampal neurons impairs expression of recent but not remote contextual fear memories. Second, using two independent interventions to manipulate hippocampal neurogenesis levels, we found that post-training increases in hippocampal neurogenesis induce forgetting of recent but not remote contextual fear memories. This pattern of results suggests that older contextual fear memories are invulnerable to fluctuations in hippocampal neurogenesis levels because they no longer depend upon the hippocampus for their expression. In doing so, they identify a boundary condition for neurogenesismediated forgetting of memories that depend upon the hippocampus during acquisition.

We previously found that increasing hippocampal neurogenesis after training weakens established hippocampus-dependent memories (Akers et al., 2014; Epp et al., 2016; Ishikawa et al., 2016), consistent with a number of theoretical predictions (Nottebohm, 1985; Barnea and Nottebohm, 1994; Deisseroth et al., 2004; Weisz and Argibay, 2012; Frankland et al., 2013; see also Rakic, 1985). In these studies, forgetting was observed regardless of whether environmental, pharmacological, or genetic interventions were used to manipulate hippocampal neurogenesis levels. Moreover, post-training increases in hippocampal neurogenesisinduced forgetting in both aversively motivated (e.g., contextual fear conditioning, inhibitory avoidance, water maze, Barnes maze) and appetitively motivated (e.g., odor-context paired associates) hippocampus-dependent tasks (Akers et al., 2014; Epp et al., 2016; Ishikawa et al., 2016). Finally, increasing hippocampal neurogenesis using these methods induced forgetting in three rodent species (mice, guinea pigs, and degus) (Akers et al., 2014; but for possible exception in rats, see Kodali et al., 2016). Here we additionally show that these forgetting effects are not sex-dependent. Post-training increases in hippocampal neurogenesis-induced equivalent forgetting in male and female mice.

Although neurogenesis-regulated forgetting of established hippocampus-dependent memories appears to generalize across a wide range of experimental conditions, boundary conditions do exist. For example, post-training increases in hippocampal neurogenesis do not affect hippocampus-independent memories. Increasing hippocampal neurogenesis following conditioned taste aversion training did not alter subsequent aversion (Akers et al., 2014). We also previously found that memory strength modu- 
lated vulnerability to exercise-induced increases in hippocampal neurogenesis. When mice were conditioned using 8 (instead of 3 ) foot shocks, post-training exercise was less effective in inducing forgetting (Akers et al., 2014). The current study identifies memory age as another boundary condition. Artificially elevating hippocampal neurogenesis, either through voluntary exercise or genetic intervention, only weakened recently acquired (but not remoteacquired) contextual fear memories.

This time-dependent change in sensitivity is most likely related to a systems consolidation process (Frankland and Bontempi, 2005). In the current study, we showed that inhibition of neural activity in the dorsal hippocampus impairs retrieval of recent, but not remote, contextual fear memories. The absence of effects of $\mathrm{CNO}$ treatment in mice expressing the control (rather than hM4Di) vector indicates that the behavioral effects are unlikely to be due to off-target effects of CNO. This chemogenetic experiment adds to a number of other studies showing that hippocampal disruption preferentially affects recent versus remote contextual fear memories. Our finding that increasing hippocampal neurogenesis, genetically or via voluntary exercise, also preferentially affects recent versus remote contextual fear memories adds to this pattern of temporally graded effects. It appears that a variety of interventions that permanently destroy (e.g., lesions) (Kim and Fanselow, 1992; Anagnostaras et al., 1999; Debiec et al., 2002; Restivo et al., 2009; Winocur et al., 2009; but see Sutherland and Lehmann, 2011; Ocampo et al., 2017), temporarily inactivate (Experiment 1) (Kitamura et al., 2009; Wiltgen et al., 2010; Goshen et al., 2011; Varela et al., 2016), or simply promote remodeling of hippocampal circuits (e.g., artificially elevating neurogenesis; Experiments 4-7) preferentially impact recently (but not remotely) acquired information.

It is this neurogenesis-mediated remodeling of hippocampal circuits that we have hypothesized as the cause of forgetting (Frankland et al., 2013; Akers et al., 2014; Richards and Frankland, 2017). As new neurons integrate into hippocampal circuits, they compete with existing granule cells for input and output connections. Because, at least to some extent, successful memory recall likely involves recapitulation of the spatiotemporal patterns of activity that occurred at the time of encoding (e.g., Richards and Frankland, 2013; Josselyn et al., 2015; Tonegawa et al., 2015), the addition of new synaptic connections and elimination of existing connections progressively reduces the likelihood of those patterns being successfully reactivated (given the same neural input or retrieval cue). According to this model, the likelihood of pattern completion failure should depend on levels of posttraining hippocampal neurogenesis. Here we found this to be the case. Changes in levels of post-training hippocampal neurogenesis depended upon the duration of voluntary exercise, and significant forgetting was observed only with $\geq 14 \mathrm{~d}$ of exercise.

Models of systems consolidation have typically proposed that some form of clearance mechanism of memory traces from the hippocampus. For instance, McClelland et al. (1995) proposed that hippocampal traces are gradually degraded as those memories are integrated into the cortex. Hippocampal neurogenesis represents one biologically plausible mechanism for this clearance (i.e., $D_{h}$ ) (McClelland et al., 1995), and such a clearance process has been hypothesized to be necessary for generalization and cognitive flexibility (Richards and Frankland, 2017). Because the hippocampus is thought to encode all experiences, but not all memories are ultimately retained, it seems likely that memory fate then depends on the outcome of a competition between proconsolidation processes (e.g., reactivation leading to successful cortical consolidation) versus clearance processes (e.g., synaptic remodeling as a consequence of hippocampal remodeling). According to this model, frequently reactivated memory traces survive because they can outstrip neurogenesis-mediated decay and be successfully consolidated in the cortex (and, in doing so, become insensitive to interventions that promote remodeling of hippocampal circuits). In contrast, infrequently reactivated traces eventually succumb to neurogenesis-mediated clearance and become inaccessible.

\section{References}

Akers KG, Martinez-Canabal A, Restivo L, Yiu AP, De Cristofaro A, Hsiang HL, Wheeler AL, Guskjolen A, Niibori Y, Shoji H, Ohira K, Richards BA, Miyakawa T, Josselyn SA, Frankland PW (2014) Hippocampal neurogenesis regulates forgetting during adulthood and infancy. Science 344: 598-602. CrossRef Medline

Anagnostaras SG, Maren S, Fanselow MS (1999) Temporally graded retrograde amnesia of contextual fear after hippocampal damage in rats: within-subjects examination. J Neurosci 19:1106-1114. Medline

Arruda-Carvalho M, Sakaguchi M, Akers KG, Josselyn SA, Frankland PW (2011) Posttraining ablation of adult-generated neurons degrades previously acquired memories. J Neurosci 31:15113-15127. CrossRef Medline

Barnea A, Nottebohm F (1994) Seasonal recruitment of hippocampal neurons in adult free-ranging black-capped chickadees. Proc Natl Acad Sci U S A 91:11217-11221. CrossRef Medline

Clelland CD, Choi M, Romberg C, Clemenson GD Jr, Fragniere A, Tyers P, Jessberger S, Saksida LM, Barker RA, Gage FH, Bussey TJ (2009) A functional role for adult hippocampal neurogenesis in spatial pattern separation. Science 325:210-213. CrossRef Medline

Creer DJ, Romberg C, Saksida LM, van Praag H, Bussey TJ (2010) Running enhances spatial pattern separation in mice. Proc Natl Acad Sci U S A 107:2367-2372. CrossRef Medline

Debiec J, LeDoux JE, Nader K (2002) Cellular and systems reconsolidation in the hippocampus. Neuron 36:527-538. CrossRef Medline

Deisseroth K, Singla S, Toda H, Monje M, Palmer TD, Malenka RC (2004) Excitation-neurogenesis coupling in adult neural stem/progenitor cells. Neuron 42:535-552. CrossRef Medline

Epp JR, Silva Mera R, Köhler S, Josselyn SA, Frankland PW (2016) Neurogenesis-mediated forgetting minimizes proactive interference. Nat Commun 7:10838. CrossRef Medline

Frankland PW, Bontempi B (2005) The organization of recent and remote memories. Nat Rev Neurosci 6:119-130. CrossRef Medline

Frankland PW, Köhler S, Josselyn SA (2013) Hippocampal neurogenesis and forgetting. Trends Neurosci 36:497-503. CrossRef Medline

Goshen I, Brodsky M, Prakash R, Wallace J, Gradinaru V, Ramakrishnan C, Deisseroth K (2011) Dynamics of retrieval strategies for remote memories. Cell 147:678-689. CrossRef Medline

Imayoshi I, Sakamoto M, Ohtsuka T, Takao K, Miyakawa T, Yamaguchi M, Mori K, Ikeda T, Itohara S, Kageyama R (2008) Roles of continuous neurogenesis in the structural and functional integrity of the adult forebrain. Nat Neurosci 11:1153-1161. CrossRef Medline

Ishikawa R, Fukushima H, Frankland PW, Kida S (2016) Hippocampal neurogenesis enhancers promote forgetting of remote fear memory after hippocampal reactivation by retrieval. eLife 5:e17464. CrossRef Medline

Josselyn SA, Köhler S, Frankland PW (2015) Finding the engram. Nat Rev Neurosci 16:521-534. CrossRef Medline

Kim JJ, Fanselow MS (1992) Modality-specific retrograde amnesia of fear. Science 256:675-677. CrossRef Medline

Kitamura T, Saitoh Y, Takashima N, Murayama A, Niibori Y, Ageta H, Sekiguchi M, Sugiyama H, Inokuchi K (2009) Adult neurogenesis modulates the hippocampus-dependent period of associative fear memory. Cell 139:814-827. CrossRef Medline

Kodali M, Megahed T, Mishra V, Shuai B, Hattiangady B, Shetty AK (2016) Voluntary running exercise-mediated enhanced neurogenesis does not obliterate retrograde spatial memory. J Neurosci 36:8112-8122. CrossRef Medline

Marino S, Vooijs M, van Der Gulden H, Jonkers J, Berns A (2000) Induction of medulloblastomas in p53-null mutant mice by somatic inactivation of $\mathrm{rb}$ in the external granular layer cells of the cerebellum. Genes Dev 14: 994-1004. CrossRef Medline

McClelland JL, McNaughton BL, O’Reilly RC (1995) Why there are complementary learning systems in the hippocampus and neocortex: insights 
from the successes and failures of connectionist models of learning and memory. Psychol Rev 102:419-457. CrossRef Medline

Nottebohm F (1985) Neuronal replacement in adulthood. Ann N Y Acad Sci 457:143-161. CrossRef Medline

Ocampo AC, Squire LR, Clark RE (2017) Hippocampal area CA1 and remote memory in rats. Learn Mem 24:563-568. CrossRef Medline

Paxinos G, Franklin KBJ (2012) The Mouse Brain in Stereotaxic Coordinates (Gulf Professional Publishing).

Rakic P (1985) Limits of neurogenesis in primates. Science 227:1054-1056. CrossRef Medline

Restivo L, Vetere G, Bontempi B, Ammassari-Teule M (2009) The formation of recent and remote memory is associated with time-dependent formation of dendritic spines in the hippocampus and anterior cingulate cortex. J Neurosci 29:8206-8214. CrossRef Medline

Richards BA, Frankland PW (2013) The conjunctive trace. Hippocampus 23:207-212. CrossRef Medline

Richards BA, Frankland PW (2017) The persistence and transience of memory. Neuron 94:1071-1084. CrossRef Medline

Sahay A, Scobie KN, Hill AS, O'Carroll CM, Kheirbek MA, Burghardt NS, Fenton AA, Dranovsky A, Hen R (2011) Increasing adult hippocampal neurogenesis is sufficient to improve pattern separation. Nature 472:466470. CrossRef Medline

Saxe MD, Battaglia F, Wang JW, Malleret G, David DJ, Monckton JE, Garcia AD, Sofroniew MV, Kandel ER, Santarelli L, Hen R, Drew MR (2006) Ablation of hippocampal neurogenesis impairs contextual fear conditioning and synaptic plasticity in the dentate gyrus. Proc Natl Acad Sci U S A 103:17501-17506. CrossRef Medline

Shors TJ, Miesegaes G, Beylin A, Zhao M, Rydel T, Gould E (2001) Neurogenesis in the adult is involved in the formation of trace memories. Nature 410:372-376. CrossRef Medline

Stone SS, Teixeira CM, Devito LM, Zaslavsky K, Josselyn SA, Lozano AM,
Frankland PW (2011) Stimulation of entorhinal cortex promotes adult neurogenesis and facilitates spatial memory. J Neurosci 31:13469-13484. CrossRef Medline

Sutherland RJ, Lehmann H (2011) Alternative conceptions of memory consolidation and the role of the hippocampus at the systems level in rodents. Curr Opin Neurobiol 21:446-451. CrossRef Medline

Tonegawa S, Liu X, Ramirez S, Redondo R (2015) Memory engram cells have come of age. Neuron 87:918-931. CrossRef Medline

van Praag H, Christie BR, Sejnowski TJ, Gage FH (1999a) Running enhances neurogenesis, learning, and long-term potentiation in mice. Proc Natl Acad Sci U S A 96:13427-13431. CrossRef Medline

van Praag H, Kempermann G, Gage FH (1999b) Running increases cell proliferation and neurogenesis in the adult mouse dentate gyrus. Nat Neurosci 2:266-270. CrossRef Medline

Varela C, Weiss S, Meyer R, Halassa M, Biedenkapp J, Wilson MA, Goosens KA, Bendor D (2016) Tracking the time-dependent role of the hippocampus in memory recall using DREADDs. PLoS One 11:e0154374. CrossRef Medline

Weisz VI, Argibay PF (2012) Neurogenesis interferes with the retrieval of remote memories: forgetting in neurocomputational terms. Cognition 125:13-25. CrossRef Medline

Wiltgen BJ, Zhou M, Cai Y, Balaji J, Karlsson MG, Parivash SN, Li W, Silva AJ (2010) The hippocampus plays a selective role in the retrieval of detailed contextual memories. Curr Biol 20:1336-1344. CrossRef Medline

Winocur G, Frankland PW, Sekeres M, Fogel S, Moscovitch M (2009) Changes in context-specificity during memory reconsolidation: selective effects of hippocampal lesions. Learn Mem 16:722-729. CrossRef Medline

Zhuo JM, Tseng HA, Desai M, Bucklin ME, Mohammed AI, Robinson NT, Boyden ES, Rangel LM, Jasanoff AP, Gritton HJ, Han X (2016) Young adult born neurons enhance hippocampal-dependent performance via influences on bilateral networks. eLife 5:e22429. CrossRef Medline 